\title{
KAEDAH MENGALAMI-MENGHAYATI DALAM PENGAJARAN BAHASA IBAN DENGAN MENGGUNAKAN ENSERA
}

\author{
(EXPERIENCE-IMMERSED METHOD \\ USING 'ENSERA' IN IBAN LANGUAGE TEACHING) \\ Doratya Anak Gerry \\ doratyagerry94@gmail.com \\ Chemaline Anak Osup \\ chemaline@fbk.upsi.edu.my \\ Universiti Pendidikan Sultan Idris \\ Tanjong Malim, Perak \\ Malaysia
}

Received: 5 August 2019; Accepted: 9 November 2020

\begin{abstract}
This study was conducted to identify methods and techniques employed by teachers when they teach the Iban language using 'ensera' or folk tales. 'Ensera' refers to traditional Iban folklore about heroes from the mystical world of Panggau Libau that is shared through 'kanaka' (songs) interspersed with explanation and conversation in the form of prose. The research design utilised the qualitative approach by executing fieldwork involving 10 teachers at SMK Engkilili, Lubok Antu, Sarawak. Data was collected using a semi-structured interview and a checklist. The constructivist and moral theories were employed to analyse the methods and techniques as well as assess the teachers' mastery of the 'ensera'. Results were obtained by analysing interview transcripts. Findings revealed that the technique of 'mengalami-menghayati' (experienceimmersed) was one of the best practices in the context of teaching using 'ensera'. The teaching techniques used were identified through various classroom activities such as reading, storytelling and acting. Teaching Iban language using 'ensera' might also promote values such as courage, humanity, goodwill, diligence, patience and generosity. Therefore, the technique of 'mengalamimenghayati' should be made routine by Iban language teachers. Consequently, students might be able to express themselves well as a result of the knowledge, opinion, experience, enjoyment and appreciation derived from the learning of the Iban language through 'ensera'.
\end{abstract}

Keyword: Experience-immersed method, teaching technique, value of ensera.

\begin{abstract}
Abstrak
Kajian ini dijalankan untuk mengenal pasti kaedah dan teknik pengajaran guru dalam pengajaran bahasa Iban menggunakan ensera. Ensera merupakan cerita tradisional masyarakat Iban yang membawa kisah kepahlawanan wira-wira dari Panggau Libau (dunia kayangan) yang disampaikan secara kanaka (lagu), tetapi diselang-seli dengan sedikit penerangan dan perbualan dalam bentuk prosa. Reka bentuk kajian yang digunakan ialah kualitatif secara bertulis dengan menggunakan kajian lapangan. Kajian ini melibatkan 10 orang guru di SMK Engkilili, Lubok Antu, Sarawak. Data dikumpul dengan menggunakan kaedah temu bual berbentuk separa


berstruktur dan menggunakan instrumen senarai semak. Teori Konstruktivisme dan Teori Moral dimanfaatkan untuk melihat kaedah dan teknik serta tahap penilaian nilai dalam ensera. Hasil kajian ini digunakan untuk mengetahui tahap kepakaran guru-guru terhadap ensera. Data dianalisis dengan menghuraikan jawapan transkripsi temu bual secara bertulis bagi menjawab objektif yang terlibat. Dapatan kajian menunjukkan peranan kaedah mengalami-menghayati ialah satu model amalan terbaik dalam konteks pengajaran ensera. Teknik pengajaran yang digunakan untuk mengajar ensera dapat dikenal pasti melalui aktiviti-aktiviti yang diaplikasikan di dalam kelas seperti teknik kerusi panas, teknik membaca, teknik bercerita, dan teknik lakonan. Dengan itu, pengajaran bahasa Iban menggunakan ensera dapat memberikan kesedaran terhadap penguasaan nilai-nilai murni seperti keberanian, kemanusiaan, dan kemasyarakatan dapat mendorong melakukan kebaikan, membentuk sikap kerajinan, sabar menjalani kehidupan serta memupuk sikap pemurah. Kaedah mengalami-menghayati adalah salah satu cadangan yang harus dijadikan rutin harian kepada para guru bahasa Iban di sekolah. Implikasinya ialah pelajar boleh memberikan pendapat yang sangat baik melalui pengetahuan, pendapat dan pengalaman, penikmatan dan penghayatan dalam pengajaran bahasa Iban dengan menggunakan ensera.

Kata kunci: Kaedah mengalami-menghayati, teknik pengajaran, nilai ensera.

\section{Pengenalan}

Ensera ialah cerita tradisional suku kaum Iban yang berbentuk kisah kepahlawanan dari Panggau Libau di kayangan (the raised world). Penyampaian ensera atau sera biasanya dikanaka (dilagukan) tetapi diselang-seli dengan sedikit penerangan dan perbualan dalam bentuk prosa (Noriah Taslim dan Chemaline Osup, 2013, p. 43). Struktur ensera adalah puisi naratif yang amat panjang dan terdapat ensera mengandungi 30,000 baris dan mengambil masa bermalam-malam untuk diceritakan kerana pendengar perlu mengikuti jalan ceritanya dari awal hingga ke akhir. Ketertarikan pendengar terhadap ensera bergantung kepada kemahiran bercerita, lenggok lagu dan suara pencerita. Pada masa dahulu, ensera berperanan sebagai hiburan utama kaum Iban, terutamanya dari segi menghiburkan mereka yang telah penat lelah bekerja pada waktu siang sehinggakan mereka dapat menghilangkan rasa bosan dan letih setelah melakukan kerja sepanjang hari. Selain itu, ensera turut berfungsi sebagai aktiviti sosial di rumah panjang bagi masyarakat Iban dan mengeratkan hubungan silaturahim mereka.

Pada dasarnya, kaedah pengajaran yang menggunakan pendekatan ensera tidak diperkenalkan secara serius di sekolah sekitar Sarawak. Pengajaran bahasa Iban dengan menggunakan ensera hanya disampaikan secara umum sahaja, iaitu hanya ingin mendedahkan nilai-nilai murni yang terdapat dalam sesebuah cerita kepada pelajar. Sesungguhnya kearifan guru Bahasa Iban dalam mengajar ensera perlu ditingkatkan lagi dari segi kaedah dan teknik pengajaran bahasa Iban. Penguasaan murid terhadap ensera bergantung kepada cara seseorang guru menyampaikannya. Oleh itu, kajian ini membincangkan kaedah mengalami-menghayati dalam pengajaran bahasa Iban menggunakan ensera. Mengalami-menghayati adalah satu kaedah yang digunakan oleh seseorang guru untuk mengajar sastera di dalam kelas. Menurut Goodman (1962), kaedah ini merupakan suatu pengalaman yang dikaji mengikut pandangan yang dirasa oleh pembaca itu sendiri. Hasil daripada pengalaman tersebut memberi kesan penghayatan dan kepada pendengar atau pembaca. 


\section{Permasalahan Kajian}

Kini, tradisi bercerita telah pupus dan pencerita ensera sukar ditemui. Perkara ini menyebabkan kebudayaan ini tidak diwarisi kepada golongan muda dan mereka tidak lagi mengenal cerita warisan ini. Ini dibuktikan melalui pengalaman Noriah Taslim dan Chemaline Osup (2016, p. 53) ketika melakuan penelitian ke atas Ensera, pada ketika itu, mereka mendapati bahawa hanya beberapa informan sahaja yang mampu membuat persembahan ensera. Walaupun mereka berjaya merakamkan cerita, namun teks yang diperoleh tidak cukup mantap untuk diterbitkan. Menurut Magdeline Nor dan Zamri Mahamod (2014, p. 217), guru Iban yang mengajar mata pelajaran Bahasa Melayu, Bahasa Inggeris, dan Sains diberi tugas untuk mengajar Bahasa Iban. Oleh itu, pengajaran bahasa Iban terutamanya yang menggunakan ensera masih lagi belum memuaskan kerana guru-guru tersebut tidak mempunyai pengalaman mengajar ensera, kekurangan bahan untuk menyampaikan ensera, tidak memahami kosa kata dan isi tersirat serta kaedah dan teknik yang digunakan oleh guru tersebut sukar untuk difahami oleh pelajar. Kesannya, pelajar mudah berasa bosan dan hilang tumpuan semasa sesi pengajaran dan pembelajaran menyebabkan ilmu terhadap pengajaran ensera tidak sepenuhnya dikuasai di dalam kelas.

Berdasarkan pihak pelajar pula, mereka mungkin berpersepsi bahawa cerita rakyat yang bersifat dongeng adalah tidak logik, kurang berminat dan berasa malu untuk membaca cerita rakyat dalam bahasa Iban. Ini mengakibatkan mereka kurang mengetahui jenis-jenis ensera, kurang arif menguasai ensera dan gagal memahami gaya cerita yang terkandung dalam ensera. Guru memainkan peranan dalam kesemua pengalaman dan pengetahuannya mengenai sesuatu aspek penyampaian terutamanya dalam bidang pengajaran agar pelajar atau pembaca mendapat dan merasai sesebuah pengalaman yang berguna daripada guru-guru mereka. Berdasarkan latar belakang permasalahan yang telah dinyatakan kajian ini berusaha untuk mencapai tiga objektif kajian, iaitu mengenal pasti kaedah dan teknik pengajaran guru dalam pengajaran bahasa Iban, menjelaskan amalan terbaik dalam pembelajaran dan pemudahcara bahasa Iban berdasarkan kaedah dan teknik pengajaran ensera dan menghuraikan nilai yang terdapat dalam ensera yang digunakan dalam kaedah dan teknik pengajaran. Soalan-soalan kajian yang membantu dalam mencapai tiga objektif ini ialah apakah kaedah dan teknik pengajaran guru dalam pengajaran bahasa Iban, apakah amalan terbaik dalam pembelajaran dan pemudah cara bahasa Iban berdasarkan kaedah dan teknik pengajaran ensera digunakan dan apakah nilai yang terdapat dalam ensera yang digunakan dalam kaedah dan teknik pengajaran.

\section{Teori Kajian}

Kajian ini melibatkan dua gabungan teori, iaitu teori konstruktivisme dan teori moral. Menurut Kamarudin Hj. Husin (2010, p. 404), konstruktivisme dapat diselaraskan dengan pendekatan kognitif yang memberi kesan kepentingan dalam semua aspek teori pembelajaran, contohnya cara bagaimana pengetahuan ditanggapi dan dikuasai, jenis pengetahuan, kemahiran dan aktiviti yang ditekankan, peranan pelajar dan guru dan bagaimana matlamat dibina, kesemuanya dipersembahkan dalam bentuk yang berbeza-beza dalam perspektif kontruktivisme. Melalui definisi ini, wajarlah pengkaji menggunakan teori konstruktivisme dalam kajiannya kerana teori ini berkaitan dengan kaedah serta teknik pengajaran guru bahasa Iban dalam mengajar ensera dengan menggunakan kaedah mengalami-menghayati khususnya guru dapat mengaplikasikan 
pelbagai aktiviti seperti teknik bercerita, membaca, dan sebagainya untuk mengasah pengetahuan sedia ada pelajar. Di samping itu, beliau turut menyatakan bahawa proses menggunakan teori konstruktivisme ini tidak mementingkan kesalahan pelajar, tetapi sebagai saluran untuk mendapatkan gagasan bagaimana pelajar dapat mengorganisasi dunia pengalaman mereka (Kamarudin Hj. Husin, 2010, p. 405). Menurut Syahida Nadia Zakaria (2015, p. 13), pendekatan konstruktivisme dijelaskan dalam kajian beliau bagi menentukan keberkesanan dari segi peningkatan prestasi pelajar. Pendekatan konstruktivisme merupakan proses pembelajaran yang menerangkan bagaimana pengetahuan disusun dalam minda murid. Pengetahuan dikembangkan secara aktif oleh pelajar itu sendiri dan tidak diterima secara pasif dari persekitarannya. Hal ini bermakna, pembelajaran merupakan hasil daripada usaha murid itu sendiri dari pengalaman sedia ada mereka dan bukan dipindahkan daripada guru kepada murid. Bagi membantu murid membina konsep atau pengetahuan baru, guru perlu mengambil kira struktur kognitif yang sedia ada pada mereka. Setelah maklumat baru disesuaikan dan diserap untuk dijadikan sebahagian daripada pegangan kuat mereka, membolehkan bentuk baru tentang sesuatu ilmu pengetahuan dapat dibina. Oleh itu, persamaan antara kajian sarjana ini dengan kajian yang dilakukan oleh pengkaji adalah dari segi teori yang digunakan, sebagai panduan teori pembelajaran berkaitan dengan pendekatan, kaedah dan teknik yang digunakan dalam pengajaran bahasa Iban khususnya yang menggunakan ensera.

Seterusnya, bagi teori moral pula bermaksud satu konsep yang dirumuskan oleh sesebuah komuniti, sosial atau budaya bagi menentukan kebaikan dan keburukan. Teori ini merupakan satu norma tentang kehidupan yang diberi kedudukan istimewa dalam kegiatan sesebuah komuniti, sosial atau budaya itu sendiri (Mana Sikana, 2014, p. 45). Norma inilah yang menentukan gerak kerja ahli-ahlinya berlandaskan sesuatu yang mulia, dihargai dan mempunyai prestij sangat tinggi. Perubahan moral berlaku disebabkan oleh zaman, sosial, kepercayaan, pendidikan, ekonomi dan dimensi-dimensi budaya yang lainnya. Dari segi sastera, seseorang yang membaca sesebuah karya mempunyai naluri keseronokan, berdasarkan penilaian baik buruknya cerita, tinggi rendahnya mutu cerita dan kuat lemahnya kesan cerita. Penilaian sesebuah karya itu adalah berdasarkan ceritanya, secara tidak langsung aspek-aspek seperti bahan, logika dan perutusannya menjadi subjek yang turut dikemukakan dalam sesebuah cerita, kemudian dikaitkan dengan isi, tujuan isi atau cara cerita disampaikan. Unsur-unsur ini dikumpulkan dan disebut sebagai moral. Teori moral juga mempunyai satu nilai yang boleh ditakrifkan sebagai satu kepercayaan untuk mendorong pemikiran, tingkah laku dan amalan kerja seseorang atau sesebuah institusi untuk bertindak mengikut pemilihan yang berasaskan norma pada masyarakat. Nilai juga merangkumi kepercayaan dan tingkah laku yang membentuk keperibadian yang teserlah daripada sikap, kelakuan dan pegangan hidup. Oleh itu, perkaitan yang dilihat dalam kedua-dua teori ini adalah berfokus kepada pengajaran dan pembelajaran bahasa Iban menggunakan ensera.

Selain itu, berdasarkan pendapat Goodman (1962), mengalami-menghayati ialah sesuatu pengalaman yang dikaji mengikut tanggapan daripada pembaca itu sendiri. Beliau menjelaskan setiap individu mempunyai pengalaman tersendiri, iaitu hasil daripada himpunan pengalaman yang dilalui dan penilaian sendiri. Oleh itu, Goodman menekankan bahawa perkara yang dialami oleh pembaca dan melihat sejauh mana pula seseorang pembaca itu dapat menghayati rakaman penulis melalui bahasa yang disampaikan. Menurutnya lagi, mengalami-menghayati menekankan "penikmatan" agar sesuatu aspek kesusasteraan yang dipelajari itu dapat dirasakan dan dihayati sepenuhnya. Biasanya penghayatan itu bergantung kepada pengalaman-pengalaman pelajar yang digunakan untuk mendapat sesuatu pengalaman baru. Bagi aspek pengajaran dan pembelajaran kesusasteraan, pelajar-pelajar didedahkan kepada beberapa persoalan dalam sesuatu aspek yang dikaji dan langkah ini disusuli dengan aktiviti mentafsir persoalan-persoalan itu sehingga dapat merasakan jalan cerita yang terdapat pada bahan bacaan mereka (Kamarudin Hj Hussin, 1988, p. 
234). Dengan ini, kaedah mengalami-menghayati ialah satu model amalan terbaik dalam konteks pengajaran ensera. Hal ini demikian kerana guru dan pelajar dapat berkongsi pengalaman lalu untuk mendapatkan emosi dan pengalaman berdasarkan karya melalui penikmatan dan penghayatan yang dititikberatkan dalam pengajaran sastera terutamanya pengajaran ensera.

Di samping itu, nilai sering dikaitkan dengan budaya masyarakat. Pendapat Koentjaraningrat (1985), yang dipetik oleh Sesilia Seli dan Mohamad Mokhtar Abu Hassan (2017), nilai budaya merujuk kepada konsep yang berkaitan dengan pemikiran masyrakat yang dianggap bernilai, berharga, dan penting dalam kehidupan hingga nilai tersebut dijadikan sebagai pedoman yang memberikan hala dan orientasi kepada kehidupan masyarakat itu. Hal ini bermakna setiap individu menjadikan nilai sebagai pedoman dalam kehidupan untuk mengenal pasti baik buruknya sebelum membuat sesuatu keputusan dan tindakan melalui akal fikiran. Nilai juga merujuk kepada penentu matlamat sesuatu kelompok sosial, mencorakkan pola perlakuan sosial serta menentukan cara bagaimana hubungan sosial dalam masyarakat dibentuk (Mustaffa Omar, 2010). Oleh itu, pengajaran bahasa Iban menggunakan ensera dianggap sebagai satu pengajaran yang bersifat deduktif kerana mempunyai unsur nilai kepada masyrakat.

Bagi aspek pengajaran dan pembelajaran, bahasa Iban bukan satu mata pelajaran yang baru di sekolah. Mata pelajaran ini telah diajar sejak tahun 1853 di Sarawak. Pernyataan ini ditulis oleh dua sarjana tempatan, iaitu Magdeline Nor dan Zamri Mahamod (2016). Aspek pengetahuan pedagogi guru bahasa Iban pada awalnya memberi pengenalan tentang bahasa Iban yang dituturkan oleh kaum Iban di Sarawak. Kaum Iban merupakan kumpulan etnik terbesar di negeri Sarawak. Faktor ini mungkin menjadi salah satu punca jumlah murid yang mempelajari bahasa Iban jauh lebih besar berbanding etnik yang lain. Pengajaran bahasa Iban bermula di peringkat sekolah rendah hingga ke peringkat Sijil Pelajaran Malaysia (SPM) dan kini ke peringkat ijazah. Menurut Magdeline Nor dan Zamri Mahamod (2016), pengajaran bahasa Iban dianggap sebagai satu proses untuk memudahkan pembelajaran murid. Oleh sebab itu, proses pengajaran akan dikaitkan secara langsung dengan proses pembelajaran murid. Pengajaran berkesan biasanya akan melibatkan penggunaan teknik atau kaedah untuk melicinkan lagi proses pengajaran dan pembelajaran. Antara kaedah atau teknik yang sering digunakan seperti kaedah sumbang saran, tunjuk cara (demontrasi), simulasi atau kaedah pengajaran kumpulan, perbincangan atau kaedah penyelesaian masalah, audio lingual, kod kognitif, dan kaedah projek (Magdeline Nor dan Zamri Mahamod, 2016, p. 42). Pelbagai kaedah atau teknik seperti ini dapat melahirkan pengajaran dan pembelajaran yang lebih berkesan. Guru bahasa Iban yang sedia ada dan guru baharu haruslah sentiasa mengikut perkembangan strategi pengajaran yang sesuai sebagai landasan pembelajaran dan menjadi pemudah cara yang baik dengan kepakaran masingmasing bagi bahan pengajaran, keperluan bahan pengajaran, kehendak pelajar dan persekitaran pengajaran lebih mantap dari segi pembentukan ilmu yang tinggi. Menurut Chew Fong Peng (2011), guru seharusnya dapat menguasai pendekatan, kaedah, dan teknik pengajaran. Hal ini demikian kerana guru perlu menyesuaikan diri dengan isi pelajaran dan sentiasa bersikap responsif, bertimbang rasa, bertanggungjawab, tenang, berkeyakinan semasa melaksanakan pengajaran. Kaedah pengajaran dan pembelajaran yang berkesan juga perlu mempunyai ciri-ciri seperti mencabar minda pelajar serta menarik perhatian pelajar untuk menerokai isi pengajaran dengan lebih mendalam lagi khususnya dalam pengajaran sastera seperti mata pelajaran bahasa Iban menggunakan ensera.

\section{Metodologi Kajian}

Metodologi kajian merujuk kepada proses, prinsip, dan prosedur yang akan digunakan untuk mendekati permasalahan dan mencari jawapan. Kajian ini merupakan sebuah kajian yang 
berbentuk kualitatif. Pendekatan ini dipilih kerana penyelidikan lebih menjurus kepada pengumpulan maklumat tentang kaedah dan teknik pengajaran ensera oleh guru bahasa Iban. Kesemua elemen akan dinilai berlandaskan proses perlaksanaan temu bual dan senarai semak terhadap subjek kajian. Maklumat yang dikumpul adalah dalam bentuk ayat atau perkataan dan diperoleh melalui kaedah temu bual dan senarai semak.

Temu bual didefinisikan sebagai suatu proses untuk mendapatkan data dengan menemui seseorang atau satu kumpulan kecil secara bersemuka dan melakukan soal jawab secara dua hala dengan tujuan untuk meminta pandangan, pendapat dan pengakuan daripada seseorang (Ghazali Darusalam dan Sufean Hussin, 2018, p. 507). Dalam kajian ini pengkaji menggunakan soalan temu bual jenis semi berstruktur dan berbentuk protokol temu bual. Temu bual jenis semiberstruktur dipilih kerana pengkaji mempunyai kebebasan untuk menanyakan soalan yang lebih mendalam supaya mendapat jawapan yang dikehendaki. Temu bual semi berstruktur ialah penemu bual membina soalan-soalan terlebih dahulu, kemudian responden mempunyai kebebasan untuk menjawab dengan tidak terhad, dilakukan secara terbuka supaya soalan dan jawapan dapat dikembangkan lagi mengikut pengetahuan penemu bual dan respoden (Rosliah Kiting, 2016, p. 113-114). Soalan protokol temu bual mempunyai kandungan yang bersifat memberi penerangan. Pemilihan dan penyusunan soalan juga berubah dan disesuaikan mengikut dapatan yang diperoleh ketika sesi temu bual dilakukan. Penggunaan jenis temu bual ini ditafsirkan lebih fleksibel dan sesuai untuk mendapatkan maklumat lanjut dan membolehkan soalan dikemukakan mengikut keperluan objektif.

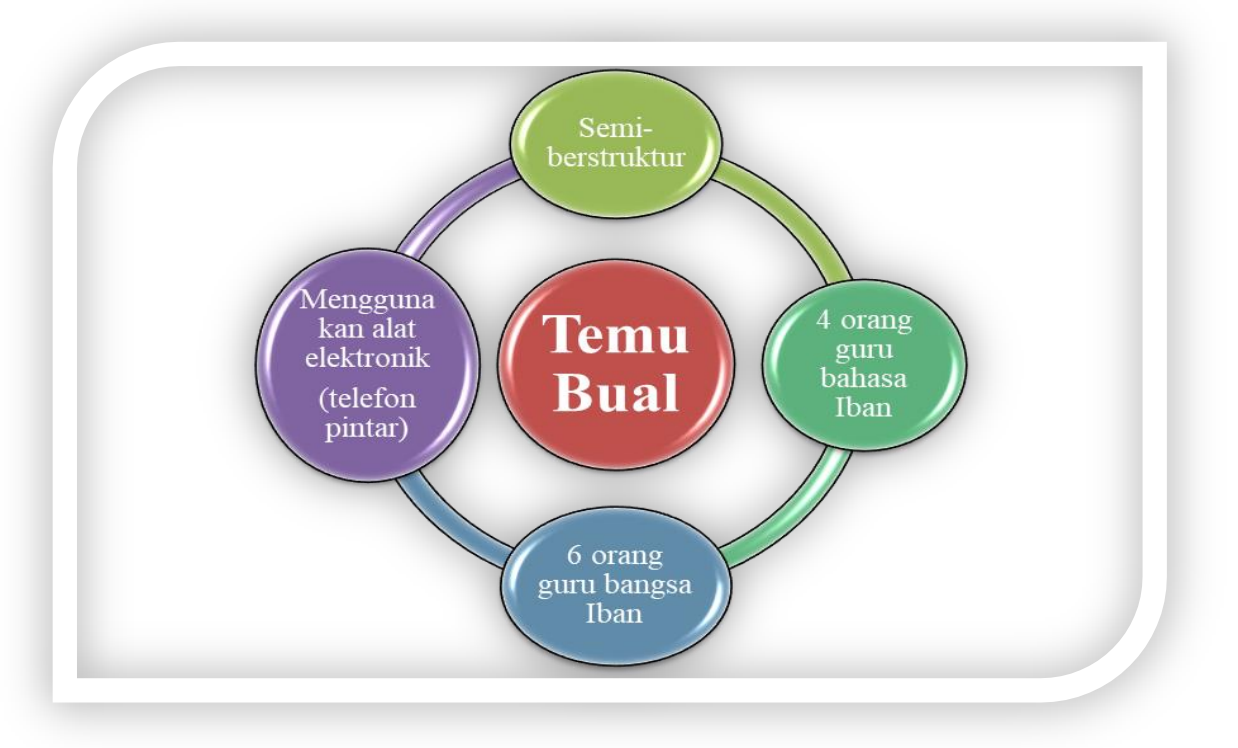

Rajah 1.1 Kaedah Temu Bual

Rajah 1.1 menunjukkan prosedur temu bual yang dijalankan. Kajian ini dilakukan melalui temu bual secara lisan (perbualan secara bersemuka), dan jawapan direkod oleh pengkaji secara bertulis dan melalui rakaman suara dengan menggunakan bahan elektronik. Definisi temu bual ialah suatu perbualan dua hala yang bertujuan untuk mengumpul maklumat kajian. Sebagai contoh, interaksi semuka antara penemu bual dan informan dijalankan dengan tujuan memperoleh maklumat daripada informan kajian secara lisan. Menurut Densin (2001 dlm. Chua, 2014), temu bual harus digunakan lebih daripada hanya sebagai alat pengumpulan maklumat yang bersifat reflektif dan dapat mencerminkan kehidupan dan keadaan sebenar mengenai sesuatu fenomena. Dalam kajian ini, pengkaji menemu bual empat orang guru bahasa Iban dan seterusnya enam orang guru yang mengajar mata pelajaran lain yang berlatar belakangkan kaum Iban sebagai penyalur maklumat. Hal ini demikian kerana guru bahasa Iban tidak mencukupi untuk mendapatkan maklumat yang diingini. Oleh itu, pengkaji telah memilih guru daripada mata 
pelajaran Bahasa Melayu, Bahasa Inggeris, dan Kesusasteraan Melayu untuk disoal jawab melalui pengalaman mereka terhadap pengetahuan tentang ensera. Tambahan lagi, guru-guru bahasa Iban yang ditemu bual mempunyai pengalaman dalam lingkungan 4 tahun sehingga 20 tahun dalam bidang pendidikan mengikut kepakaran masing-masing serta dalam bidang adat, budaya, kepercayaan dan cerita-cerita rakyat warisan.

Seterusnya pengkaji menggunakan senarai semak temu bual. Semasa menggunakan instrumen tersebut, pengkaji akan terlibat secara langsung, iaitu mendengar, merakam, memerhati sendiri fenonema yang hendak dikaji serta mencatat maklumat penting (kata kunci) dalam buku nota. Maklumat-maklumat tersebut akan dicatatkan dengan menggunakan buku nota. Dalam kajian ini, senarai semak amat penting kerana dapat mengelakkan maklumat penting daripada tercicir atau tertinggal semasa temu bual dijalankan.

Selain kajian lapangan, pengkaji juga melakukan kajian perpustakaan dengan merujuk kepada bahan-bahan yang berkaitan dengan topik kajian sepeti buku-buku dan jurnal-jurnal. Kategori bahan rujukan yang dimanfaatkan ialah seperti pedagogi pengajaran bahasa Iban, epik rakyat Iban, teori konstruktivisme, teori moral, nilai dalam budaya sesebuah masyarakat, kaedah dan teknik pengajaran dalam sastera, cabaran guru mengajar sastera dan sejarah latar belakang masyarakat Iban. Data akan dianalisis setelah semua usaha pengumpulan data selesai dilakukan. Data-data tersebut akan dihuraikan secara terperinci. Huraian data tersebut akan dimuatkan dalam dapatan kajian.

\section{Dapatan Kajian}

Kerja lapangan ini berjaya mengumpul 10 orang guru Iban untuk memberikan maklumat. Berikut adalah hasil dapatan kajian mengenai kaedah dan teknik yang digunakan oleh guru-guru Iban pengajaran dalam ensera.

Jadual 1.1 Strategi pengajaran guru bahasa Iban dalam mengajar ensera

\begin{tabular}{|l|l|l|l|}
\hline \multicolumn{1}{|c|}{ Bil } & \multicolumn{1}{|c|}{ Responden } & \multicolumn{1}{c|}{ Kaedah } & \multicolumn{1}{c|}{ Teknik } \\
\hline 1. & Guru A001 & Inkuiri & Penceritaan \\
\hline 2. & Guru B001 & Inkuiri & Membaca \\
\hline 3. & Guru C001 & Inkuiri & Bercerita \\
\hline 4. & Guru D001 & $\begin{array}{l}\text { Mengalami- } \\
\text { menghayati }\end{array}$ & Lakonan \\
\hline 5. & Guru E001 & $\begin{array}{l}\text { Mengalami- } \\
\text { menghayati }\end{array}$ & Kerusi panas \\
\hline 6. & Guru F001 & $\begin{array}{l}\text { Mengalami- } \\
\text { menghayati }\end{array}$ & Berdialog \\
\hline 7. & Guru G001 & Oral-aural & Perbincangan \\
\hline 8. & Guru H001 & Syarahan & Latih tubi \\
\hline 9. & Guru I001 & Simulasi & Perbincangan \\
\hline 10. & Guru J001 & $\begin{array}{l}\text { Mengalami- } \\
\text { menghayati }\end{array}$ & Drama \\
\hline
\end{tabular}

Jadual 1.1 di atas menunjukkan beberapa jenis kaedah dan teknik dalam pengajaran bahasa Iban dengan menggunakan ensera yang diaplikasikan oleh 10 orang guru. Guru A001, 
B001 dan C001 menggunakan kaedah inkuiri. Berdasarkan teknik pengajaran, ketiga-tiga guru ini mengaplikasikan teknik penceritaan, membaca dan bercerita dalam pengajaran bahasa Iban. Menurut pendapat mereka, pelajar dapat menyusun idea dan membentuk satu jawapan yang tepat dan akhir sekali guru dapat membimbing pelajar untuk mendapatkan pengetahuan dengan lebih mendalam mengenai pengajaran dalam ensera.

Seterusnya, guru G001 menggunakan pendekatan deduktif dan kaedah oral-aural kerana beliau kerap menggunakan teknik perbincangan di dalam kelas. Kaedah oral-aural ialah kaedah yang menggunakan cara dialog untuk dihafaz dan diikuti secara ajukan. Latih tubi dan dialog dijalankan dengan cara memberikan perhatian kepada intonasi yang betul. Guru I001 pula menjelaskan bahawa beliau gemar menggunakan kaedah simulasi kerana boleh melibatkan pelajar dalam aktiviti pengajaran seperti menggunakan teknik perbincangan. Namun begitu, fokus utama dalam kajian ini adalah menjurus kepada mengalami-menghayati dalam pengajaran bahasa Iban dengan menggunakan ensera. Berdasarkan jadual 1.1, kebanyakan guru menggunakan kaedah mengalami-menghayati dalam pengajaran ensera. Hal ini dikatakan demikian kerana guru D001, E001, F001 dan J001 menggunakan pelbagai teknik seperti teknik lakonan, teknik kerusi panas, teknik dialog dan teknik drama. Melalui aktiviti-aktiviti ini pelajar memperoleh penghayatan dan penikmatan daripada jalan cerita dalam ensera yang disampaikan dengan lebih berkesan sehingga memperoleh idea baharu. Rajah 1.2, 1.31 .4 dan 1.5 berikut merupakan teknik yang diaplikasikan oleh guru D001, E001, F001 dan J001 di dalam kelas semasa mengajar ensera:

\section{A. Mengalami-menghayati melalui teknik lakonan.}

Teknik ini dilakukan oleh guru D001 semasa mengajar di dalam kelas. Lakonan adalah satu aktiviti yang sangat digemari oleh pelajar kerana aktiviti ini merupakan satu hiburan dalam pembelajaran. Oleh hal yang demikian lakonan boleh dijadikan teknik pengajaran yang menarik. Gambar rajah 1.1 menunjukkan aktiviti guru D001 semasa mengajar ensera. 


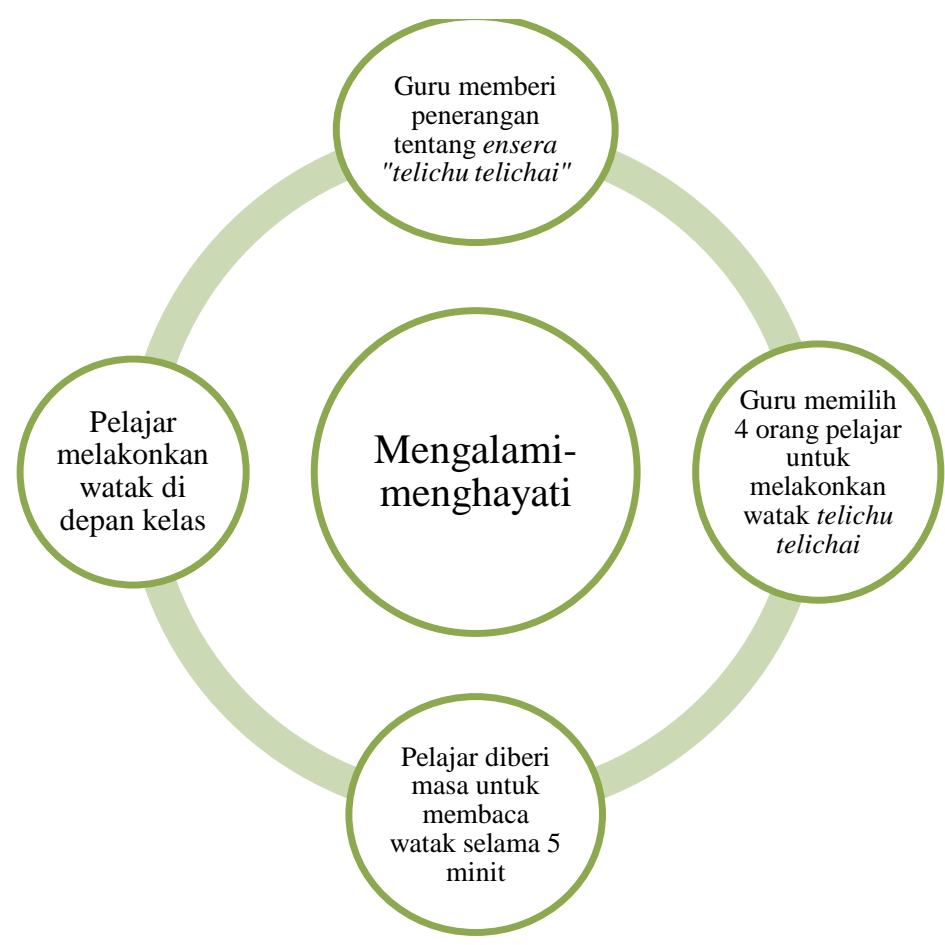

Rajah 1.2: Mengalami-menghayati dalam ensera Telichu Telichai

Berdasarkan rajah 1.2, guru D001 memberi penerangan terlebih dahulu terhadap teks ensera Telichu Telichai secara ringkas. Kisah Telichu Telichai ialah merupakan hubungan adikberadik yang sangat akrab dan sanggup berkorban untuk orang kampung demi mencari sumber makanan. Watak tersebut disampaikan oleh dua orang pelajar yang membawa watak Telichu dan Telichai, manakala dua pelajar lagi memainkan watak sebagai orang kampung. Setelah menerangkan watak dan jalan cerita, pelajar yang dipilih diarahkan untuk membawa watak masing-masing selama lima minit. Apabila keempat-empat pelajar bersedia, lakonan dimulakan dengan penuh jiwa dan perasaan. Pelajar lain menjadi penonton untuk menghayati watak yang disampaikan. Selesai sahaja lakonan dipentaskan di hadapan bilik darjah, guru memberi ganjaran kepada para pelajar yang berani dan berjaya mempersembahkan lakonan mereka dengan penuh kreativiti, seperti memberi hadiah buku cerita ensera. Akhir sekali guru membimbing pelajar untuk mengulas semula watak Telichu Telichai untuk memperoleh idea baharu, iaitu pengajaran terhadap nilai sanggup berkorban kepada masyarakat.

\section{B. Mengalami-menghayati melalui teknik kerusi panas}

Teknik ini digunakan oleh Guru E001. Teknik kerusi panas adalah satu teknik dalam latihan asas penghayatan watak dan perwatakan. Rajah 1.3 menunjukkan cara guru E001 semasa mengajar ensera. 


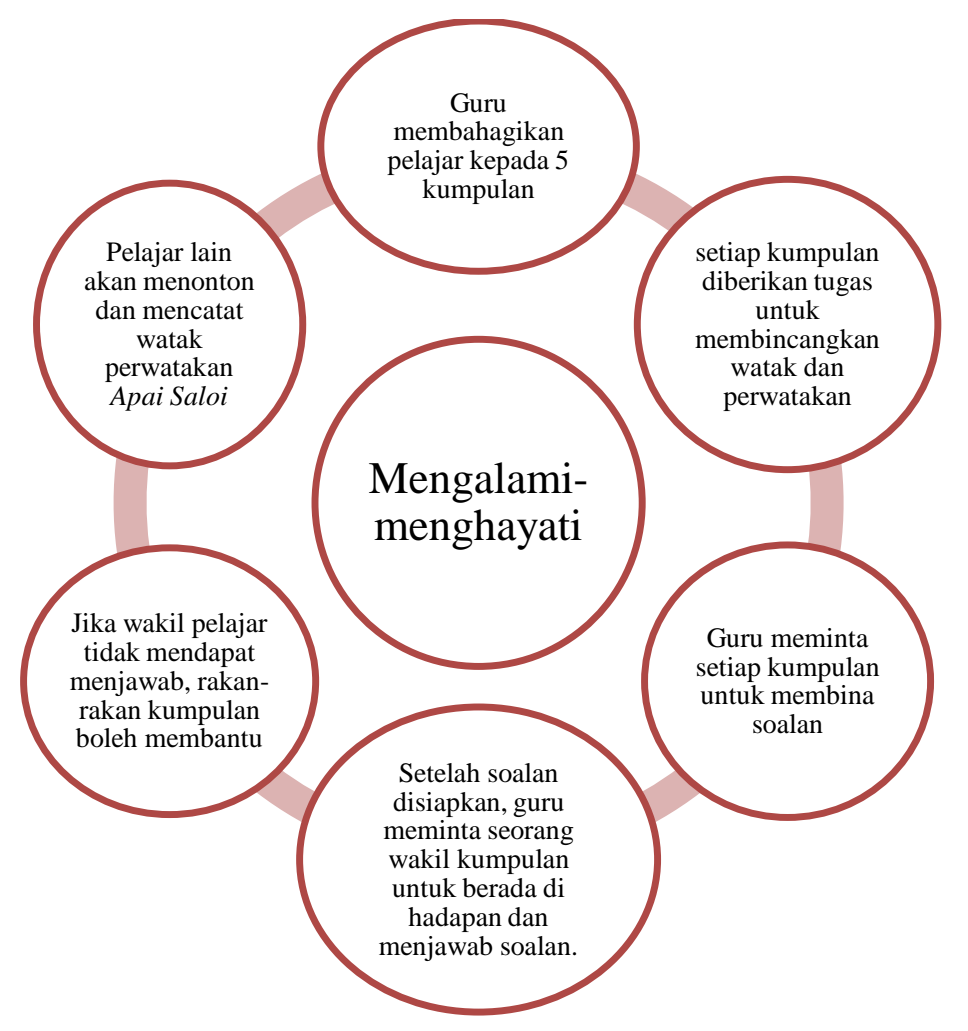

\section{Rajah 1.3: Mengalami-menghayati dalam ensera Apai Saloi}

Rajah 1.3 menunjukkan satu aktiviti menggunakan teknik kerusi panas yang diaplikasikan oleh guru E001 dalam pengajaran bahasa Iban dengan menggunakan ensera Apai Saloi. Guru membahagikan pelajar kepada lima kumpulan. Setiap kumpulan diberikan tugas untuk membincangkan watak dan perwatakan ensera Apai Saloi. Seterusnya, guru meminta setiap kumpulan tersebut untuk membina soalan daripada watak ensera Apai Saloi. Setelah soalan dibina, guru E001 meminta seorang wakil kumpulan untuk berada di hadapan bagi menjawab soalan. Jika wakil pelajar tidak dapat menjawab, rakan-rakan dalam kumpulan boleh membantu dan pelajar lain akan mencatat maklumat penting yang dihasilkan daripada watak ensera Apai Saloi. Setelah aktiviti selesai, guru E001 merumuskan watak dan perwatakan ensera Apai Saloi dengan lebih jelas. Berdasarkan teknik kerusi panas, guru E001 boleh mengasah daya ingatan pelajar dan menimbulkan keseronokan semasa belajar.

\section{Mengalami-menghayati melalui teknik berdialog}

Teknik ini ialah perbualan dalam sesebuah cerita. Pelajar biasanya diminta untuk memahami isi, perwatakan, watak, plot cerita. Seterusnya, dialog perlu dibentangkan di hadapan kelas. Dialog dapat melatih pelajar bertutur menggunakan sebutan dan intonasi yang betul. Rajah 1.4 menunjukkan pengaplikasian guru F001 semasa mengajar ensera. 


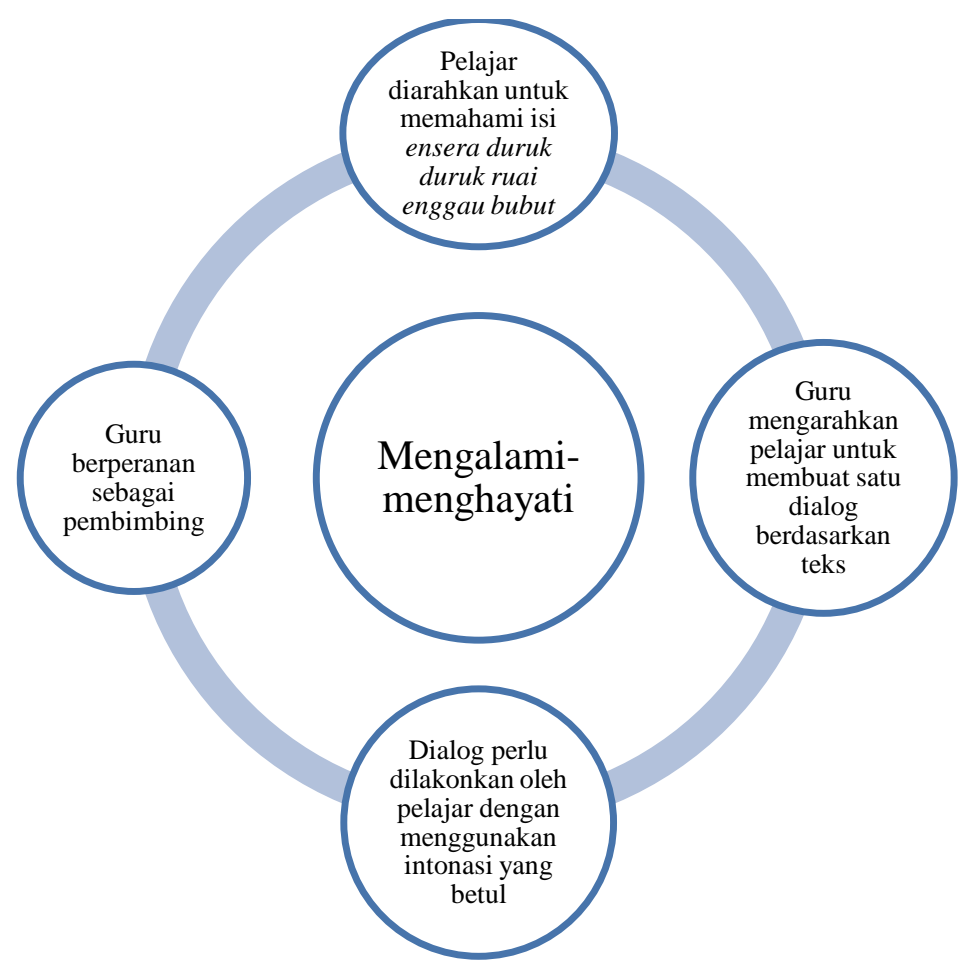

Rajah 1.4: Mengalami-menghayati dalam ensera Duruk Bubut Enggau Ruai

Rajah 1.4 menunjukkan cara guru F001 mengaplikasikan teknik berdialog dalam ensera Duruk Bubut Enggau Ruai. Pertama guru F001 mengarahkan pelajarnya supaya untuk memahami isi ensera Duruk Bubut Enggau Ruai secara senyap. Setelah pelajar memahami isi pelajaran, guru memberi arahan supaya pelajar menulis satu dialog beradasarkan teks ensera yang diberikan olehnya. Pelajar diberi masa 10 minit untuk menghasilkan dialog mengikut kreativiti dan pemahaman yang diperolehi daripada pembacaan. Dialog yang ditulis oleh pelajar perlu dilakonkan di hadapan kelas dan guru F001 memberikan lima minit untuk pelajar melakonkan fokus utama dalam ensera Duruk Bubut Enggau Ruai. Akhir sekali, setelah dialog selesai dilakukan, guru F001 memberi kesimpulan terhadap nilai pengajaran dalam ensera tersebut, dan sekaligus dapat menajamkan lagi pengetahuan pelajarnya.

\section{Mengalami-menghayati melalui teknik drama}

Teknik drama adalah cara bagaimana sesuatu pergerakan tubuh badan bergerak atau dilakonkan. Teknik ini juga dilakukan secara spontan dengan menggunakan suara ataupun isyarat. Rajah 1.5 menunjukkan aktiviti yang dilakukan oleh guru J001 menggunakan teknik drama semasa mengajar. 


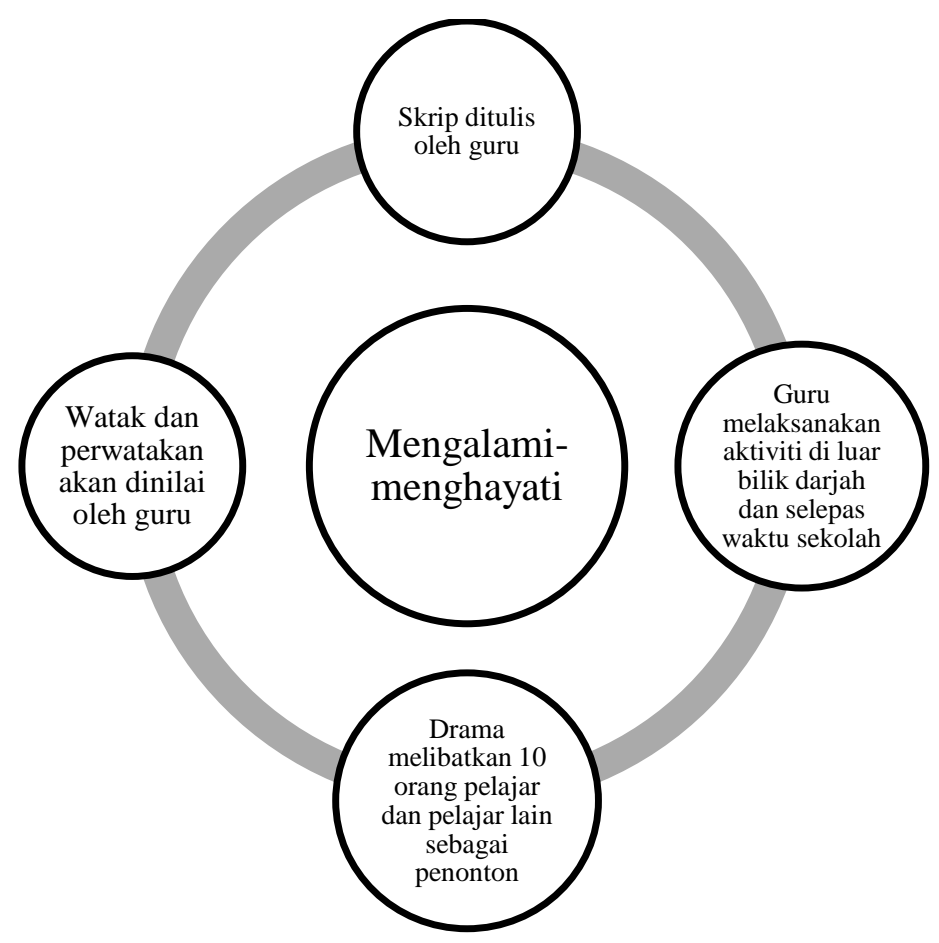

\section{Rajah 1.5: Mengalami-menghayati dalam ensera Keling dan Kumang}

Rajah 1.5 menunjukkan cara penggunaan mengalami-menghayati melalui teknik drama yang dilakukan di luar bilik darjah, iaitu dewan sekolah SMKE. Guru J001 menggunakan satu idea untuk menarik minat pelajar dalam membuat satu drama ensera Keling dan Kumang. Persekitaran yang dipilih sangat sesuai kerana guru J001 menggunakan waktu selepas persekolahan sebagai kelas tambahan pengajaran ensera. Skrip ensera Keling dan Kumang telah dicipta oleh guru J001 melalui jalan cerita mengikut pengetahuan sedia ada dan ditokok tambah agar berkaitan dengan bidang pengajaran sesuai dengan pelajar. Drama ensera Keling dan Kumang melibatkan 10 orang pelajar dan diselitkan persembahan muzik untuk memeriahkan lagi suasana. Penonton terdiri daripada pelajar tingkatan 1 dan 2, serta guru-guru Bahasa Iban pula sebagai penilai. Melalui penilaian yang dilakukan oleh juri, guru F001 dapat mengesan tahap penguasaan pelajarnya terhadap pengajaran ensera.

Berdasarkan dapatan yang diperoleh melalui temu bual guru-guru, jelaslah bahawa kaedah mengalami-menghayati adalah satu amalan terbaik dalam pengajaran bahasa Iban dengan menggunakan ensera. Kaedah ini dapat memupuk minat pelajar dan meningkatkan pengetahuan yang mendalam terhadap ensera, dan secara tidak langsung dapat mengekalkan warisan cerita rakyat masyarakat Iban.

\section{Apakah Kaedah dan Teknik Pengajaran Guru?}

Secara umumnya, kaedah bermaksud satu tindakan guru yang sistematik bertujuan untuk mencapai objektif pengajaran yang ditetapkan, lebih bercorak jangka pendek dan merupakan usaha keseluruhan yang terdiri daripada sesuatu pendekatan yang dipilih. Contohnya, guru menggunakan beberapa gambar dan meminta murid menunjukkan gambar yang sedang diceritakan dengan bahasa mereka sendiri. Kaedah ini disebut sebagai kaedah natural yang berasaskan kepada penguasaan bahasa dan situasi komunikatif (Tuan Jah Tuan Yusof, 2011, p. 88-89). Teknik pula merupakan satu kemahiran atau cara melaksanakan penyampaian bahan 
pengajaran kepada pelajar dari segi langkah-langkah dalam aktiviti pembelajaran. Secara khususnya, teknik merupakan satu cara penyampaian pelajaran dan perlu diteliti supaya dapat mempercepatkan penanggapan pelajar. Semasa proses pengajaran dan pembelajaran dilakukan, pelbagai teknik yang boleh digunakan oleh guru seperti teknik bercerita, teknik perbincangan, dan sebagainya (Sapie Sabilan, 2017, p.44).

Berdasarkan pengajaran bahasa Iban yang menggunakan ensera, kaedah dan teknik yang digunakan oleh guru dianggap sebagai satu proses yang memudahkan pembelajaran murid. Oleh sebab itu, proses pengajaran akan dikaitkan secara langsung dengan proses pembelajaran murid. Pengajaran berkesan biasanya akan melibatkan penggunaan kaedah dan teknik untuk melicinkan lagi proses pengajaran dan pembelajaran. Antara kaedah dan teknik yang sesuai semasa mengajar ensera ialah kaedah mengalami-menghayati dan teknik-teknik seperti teknik lakonan, teknik kerusi panas, teknik berdialog dan teknik drama. Dengan adanya kaedah mengalami-menghayati dan teknik-teknik tersebut, guru-guru Iban dapat meningkatkan lagi pengetahuan serta pemahaman terhadap ensera kepada para pelajar. Selain itu, dapat mempertingkatkan kemahiran menggunakan kosa kata, intonasi dan penggunaan ayat bahasa Iban yang betul semasa berkomunikasi.

\section{Kesimpulan}

Kesimpulannya, kaedah dikatakan sebagai satu loncatan kepada pengajar dan perlu dilaksanakan sebaik mungkin dengan pelbagai cara, sekurang-kurangnya menggunakan dua kaedah pengajaran. Hal ini demikian kerana guru akan mengajar perkara yang lebih mudah ke perkara yang lebih sukar. Menggunakan dua kaedah dalam setiap pengajaran dapat memberi ruang ketika penerangan secara langkah demi langkah, iaitu daripada senang kepada yang sukar bagi pelajar, seperti menggunakan kaedah mengalami-menghayati terutamanya dalam pengajaran cerita rakyat seperti ensera. Oleh itu, guru harus menerapkan kaedah ini agar pelajar belajar dengan cara yang teratur dalam pembelajaran dan menghayati pengajaran itu sepenuh jiwa dan perasaan mereka.

Walau bagaimanapun, menguasai pengetahuan kandungan sahaja tidak cukup untuk menjamin keberkesanan pengajaran seseorang guru. Teknik merupakan satu perakuan yang terperinci untuk melengkapkan proses bagi melancarkan pengajaran dan pembelajaran. Misalnya, pengajaran Bahasa Iban menggunakan ensera guru-guru Iban menggunakan teknik berlakon, teknik kerusi panas, teknik dialog dan teknik drama semasa mengajar ensera. Hal ini dapat meningkatkan lagi kemahiran intonasi bahasa Iban dengan betul. Pengajaran bahasa Iban menggunakan ensera juga harus dipertingkatkan dari segi ilmu pengetahuan tentang ensera lain yang masih lagi tidak diketahui oleh guru dan pelajar. Misalnya, mengadakan kursus-kursus CPD (Continues Professional Development) berkaitan pengajaran dan pembelajaran bahasa Iban terutamanya menggunakan ensera. Lanjutan daripada itu, keberkesanan pengajaran guru mampu memberi impak besar kepada semua pelajar terhadap keberhasilan pengajaran masing-masing mengikut kepakaran guru yang mengajar di sekolah rendah mahupun menengah serta universiti awam mengambil sastera Iban.

\section{Rujukan}

Chew Fong Peng. (2011). Pendekatan Kecerdasan Pelbagai dalam pengajaran dan pembelajaran KOMSAS. Dlm. Bahasa Melayu. Jurnal Pengajian Melayu/Journal of Malay Studies (JOMAS). 22, (111-136). 
Magdeline Nor \& Zamri Mahamod. (2014). Penterjemahan Pengetahuan Pedagogi Kandungan dalam Proses Tindakan Guru Bahasa Iban Baharu dan Berpengalaman Bukan Opsyen. Jurnal Pendidikan Malaysia. 39 (1), 37-49.

Magdeline Nor \& Zamri Mahamod. (2016). Pengetahuan pedagogi kandungan guru bahasa Iban. Bangi: Penerbit Univerisiti Kebangsaan Malaysia.

Mana Sikana. (2014). Koleksi teori Sastera: Klasik, tradisional, moden, pascamoden dan tempatan. Bangi: Penerbit Pustaka Karya.

Mustaffa Omar. (2011). Orientasi Nilai dan Penilaian Komuniti Orang Asli Dan Melayu Di Cameron Highlands: Suatu Analisis Perbandingan. Jurnal Pengajian Melayu/Journal of Malay Studies (JOMAS). 21, (171-195).

Noriah Taslim dan Chemaline Osup. (2013). Ensera Ayor. Epik Rakyat Iban, Minden, Pulau Pinang: Penerbit Universiti Sains Malaysia.

Othman Lebar. (2014). Penyelidikan Kualitatif: Pengenalan kepada teori dan metode. Tanjong Malim: Universiti Pendidikan Sultan Idris.

Rosliah Kiting. (2016). Peranan Pendidikan Talaala dan cadangan cara mewarisnkannya dalam masyarakat Kadazan Dusun, Sabah: Universiti Malaysia Sabah.

Sapie Sabilan, Suhana Mohamed Lip, Mohammad Fuad Ishak, et.al. (2016). Konsep Penerapan Dan Penghayatan Nilai-Nilai Murni Berasaskan Falsafah Pendidikan Kebangsaan (FPK). Conference: International Conference On Moslem Society 2016. (May), 1-13.

Sesilia Seli \& Mohamad Mokhtar Abu Hassan. (2017). Nilai-nilai tempatan komuniti dayakkanayatn yang wujud dalam cerita rakyat. Jurnal Pengajian Melayu/Journal of Malay Studies (JOMAS). 28, (209-251).

Syahida Nadia Zakaria. (2015). Kesan pendekatan konstruktivisme dan pendekatan tradisional dalam pengajaran dan pembelajaran komponen sastera bahasa melayu. Jurnal Pendidikan Bahasa Melayu - JPBM (Malay Language Education Journal - MyLEJ) 12.5 (2), 21804842 .

Tuan Jah Tuan Yusof. (2011). Kaedah pengajaran Bahasa Melayu sekolah rendah. Puchong, Selangor: Penerbitan Multimedia Sdn. Bhd. 